\title{
CHANGE IN MICROSTRUCTURE AT GRAIN BOUNDARIES WITH CREEP DEFORMATION OF POLYCRYSTALLINE NICKEL-BASED SUPERALLOY, IN-100 AT 1273K
}

\author{
N. Miura ${ }^{1, a}$, Y. Kondo ${ }^{1, b}$, K. Kubushiro ${ }^{2, c}$ and S. Takahashi ${ }^{2, d}$ \\ ${ }^{1}$ Department of Mechanical Systems Engineering, National Defense Academy, \\ Yokosuka Kanagawa, Japan \\ ${ }^{2}$ Research Laboratory, IHI Co. Ltd, Yokohama Kanagawa, Japan

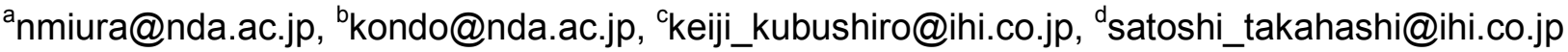

Key words: Superalloy, Creep, g' precipitates, Dislocation substructure

\begin{abstract}
The changes in the morphology of $\gamma^{\prime}$ precipitates and the dislocation substructures at the vicinity of grain boundaries with creep deformation were investigated on a polycrystalline nickel-based superalloy, IN-100. The experiments were done at $1273 \mathrm{~K}$ in the stress range of 70-180MPa with one set of samples deformed until rupture and another interrupted after reaching the minimum creep rate. The cuboidal $\gamma^{\prime}$ precipitates were regularly arrayed at the vicinity of grain boundaries and eutectic $\gamma^{\prime}$ precipitates and carbides were observed at the grain boundaries on as-heat treated IN-100. However, on both the creep interrupted and ruptured samples at all stress conditions, plate - like shaped $\gamma^{\prime}$ precipitates covered the grain boundaries. The width of the plate like shaped $\gamma^{\prime}$ precipitates increased with decreasing the stress and is wider in the creep ruptured than in the creep ruptured samples. There were few dislocations in the grains and in the plate - like shaped $\gamma^{\prime}$ precipitates, but a large number of the dislocations were observed around the interface of the plate - like shaped $\gamma$ ' precipitates. TEM observations on the specimen creep ruptured at $180 \mathrm{MPa}$ indicated that strong constant was observed at the vicinity of grain boundaries, but weak contrast in the grain interior. These results suggested that drastic plastic deformation occurred only at the vicinity of grain boundaries. Consequently, the plate - like shaped $\gamma^{\prime}$ precipitates at the grain boundaries inhibited the dislocations movement and acted as the creep strengthener.
\end{abstract}

\section{Introduction}

After accepting creep deformation, the cuboidal $\gamma^{\prime}$ precipitates in single crystal nickel-based superalloys with the stress axis of [100] orientation into the plate like ones perpendicular to the stress axis, called as the rafted $\gamma / \gamma^{\prime}$ structures [1-6]. It has been also elucidated that the rafted $\gamma / \gamma^{\prime}$ structures acted as the creep weakener [3]. The rafted $\gamma / \gamma^{\prime}$ structures was also formed in polycrystalline nickel-based superalloys on creep deformation [7-9]. In our previous work, the rafted $\gamma / \gamma^{\prime}$ plates formed parallel to the $\{001\}$ plane, irrespective to orientation of crystal grains. And it was confirmed that the formation of rafted $\gamma / \gamma^{\prime}$ structures was dependent not only on the creep testing time but also on the stress acted on the $\{001\}$ plane [9]. By the way, in polycrystalline nickel-based superalloys, the grain boundary and the eutectic $\gamma^{\prime}$ precipitates differ from those in single crystals. Especially, the grain boundaries were considered as the generation and annihilation source of dislocations during creep deformation. However, in the most studies on polycrystalline nickel-based superalloys, attention was paid to the morphology of $\gamma^{\prime}$ precipitates in the grain interior which changed remarkably during the creep deformation [7]-[9]. To clarify the effect of the grain boundaries on creep behavior, the change in the microstructures at the vicinity of grain boundaries with creep deformation must be investigated.

In this study, the changes in the morphology of $\gamma^{\prime}$ precipitates and the dislocation substructures at the vicinity of grain boundaries with creep deformation was investigated on a polycrystalline nickel-based superalloy, IN-100, creep tested at $1273 \mathrm{~K}$ in the stress range of 70 to $180 \mathrm{MPa}$. 


\section{Experimental procedure}

A polycrystalline nickel-based superalloy of $\mathrm{IN}-100$ (with a chemical composition in weight percent; Ni-10.0Cr-15.0Co-4.7Ti-5.5Al-3.0Mo-1.0V-0.18C) was prepared in form of the bars by a precision casting. The crystal bars were subjected to specified solution treatment and two-step aging treatment processes. The creep tests were carried out at $1273 \mathrm{~K}$ under constant load using initial stresses ranging from 70 to $180 \mathrm{MPa}$. Creep strain was measured automatically through the linear variable differential transformers (LVDT's) attached to an extensometer. Furthermore, some of the creep tests were interrupted at the minimum creep rate. Microstructure observations were carried out by a field emission scanning electron microscope (FE-SEM) and a transmission electron microscope (TEM). The specimens for the SEM were prepared metallographically and electroetched with a superasaturated oxialic acid aqueous solution. TEM foils were prepared by electropolishing using a twin jet polisher with the $10 \%$ perchloric acid-alcohol solution.

\section{Results and discussion}

Microstructure of as-heat treated specimens

The scanning electron micrograph of the as-heat treated IN-100 is shown in Fig.1. The cuboidal $\gamma$ ' precipitates are regularly arrayed in the $\gamma$ matrix and in the vicinity of grain boundaries. The eutectic $\gamma$ ' precipitates and carbides (dark area) are observed at the grain boundaries.

\section{Creep properties}

The stress-creep rupture life curve at $1273 \mathrm{~K}$ in stresses ranging from 70 to $180 \mathrm{MPa}$ is shown in Fig.2. The linear relation is obtained for the curve using the log-log scale.

The creep rate-time curves at $1273 \mathrm{~K}$ in stresses ranging from 70 to $180 \mathrm{MPa}$ are shown in Fig.3. All creep curves consist of the transient creep stage and the accelerating creep stage. The minimum creep rate decreases with decreasing the stress.

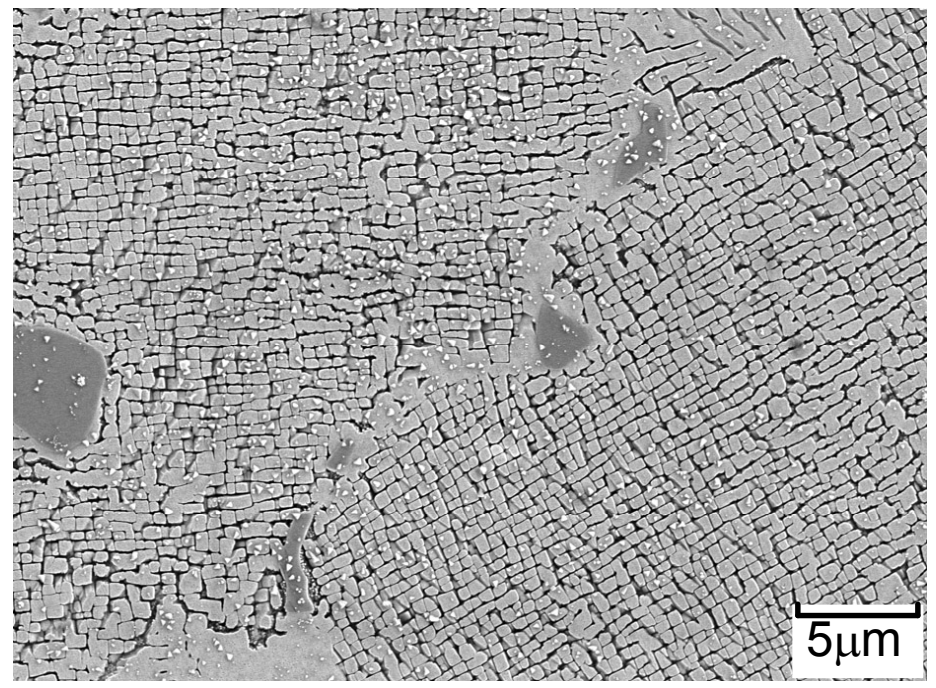

Fig.1 SEM micrograph of the as-heat treated IN-100.

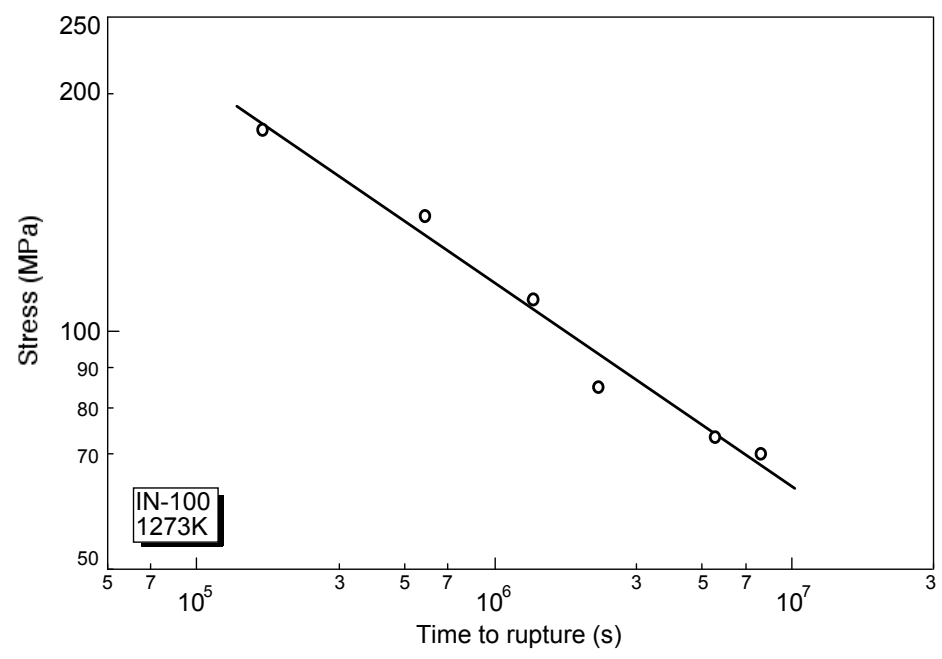

Fig.2 Stress-creep rupture life curve of $\mathrm{IN}-100$ at $1273 \mathrm{~K}$ in stresses ranging from 70 to $180 \mathrm{MPa}$

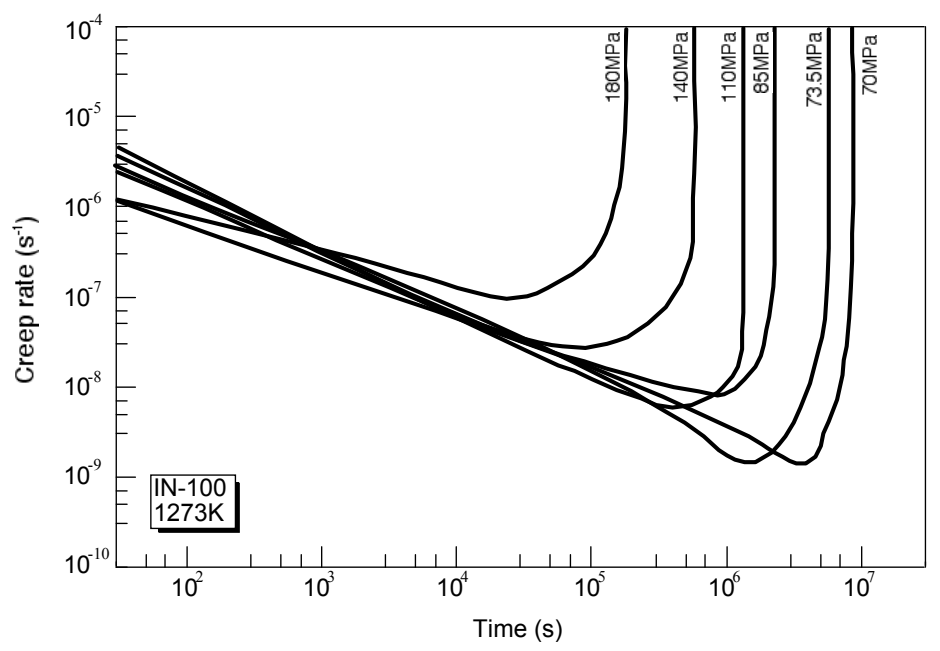

Fig.3 CDreep rate-time curves of $\mathrm{IN}-100$ at $1273 \mathrm{~K}$ in stresses ranging from 70 to $180 \mathrm{MPa}$ 


\section{Change in morphology of $\gamma^{\prime}$ precipitates at the vicinity of grain boundaries}

The SEM observations are carried out on the creep interrupted and the ruptured specimens at the vicinity of grain boundaries. The scanning electron micrographs of the creep interrupted specimens at the minimum creep rate are shown in Fig.4. The grain boundaries of the samples tested with an
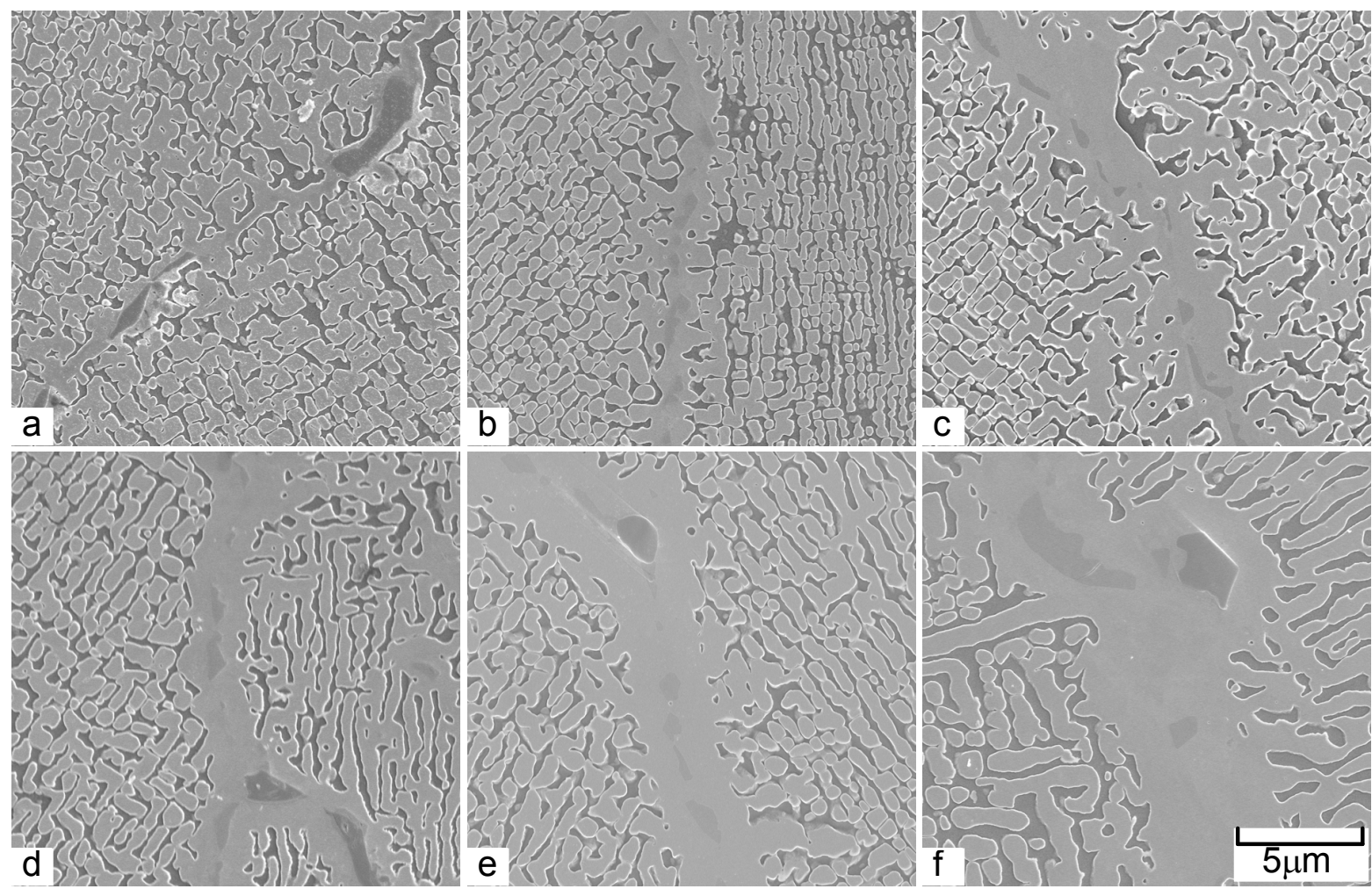

Fig.4 Scanning electron micrographs of the creep interrupted specimens at the minimum creep rate at the stress of (a) 180, (b) 140, (c) 110, (d) 85, (e) 73.5 and (f) $70 \mathrm{MPa}$.
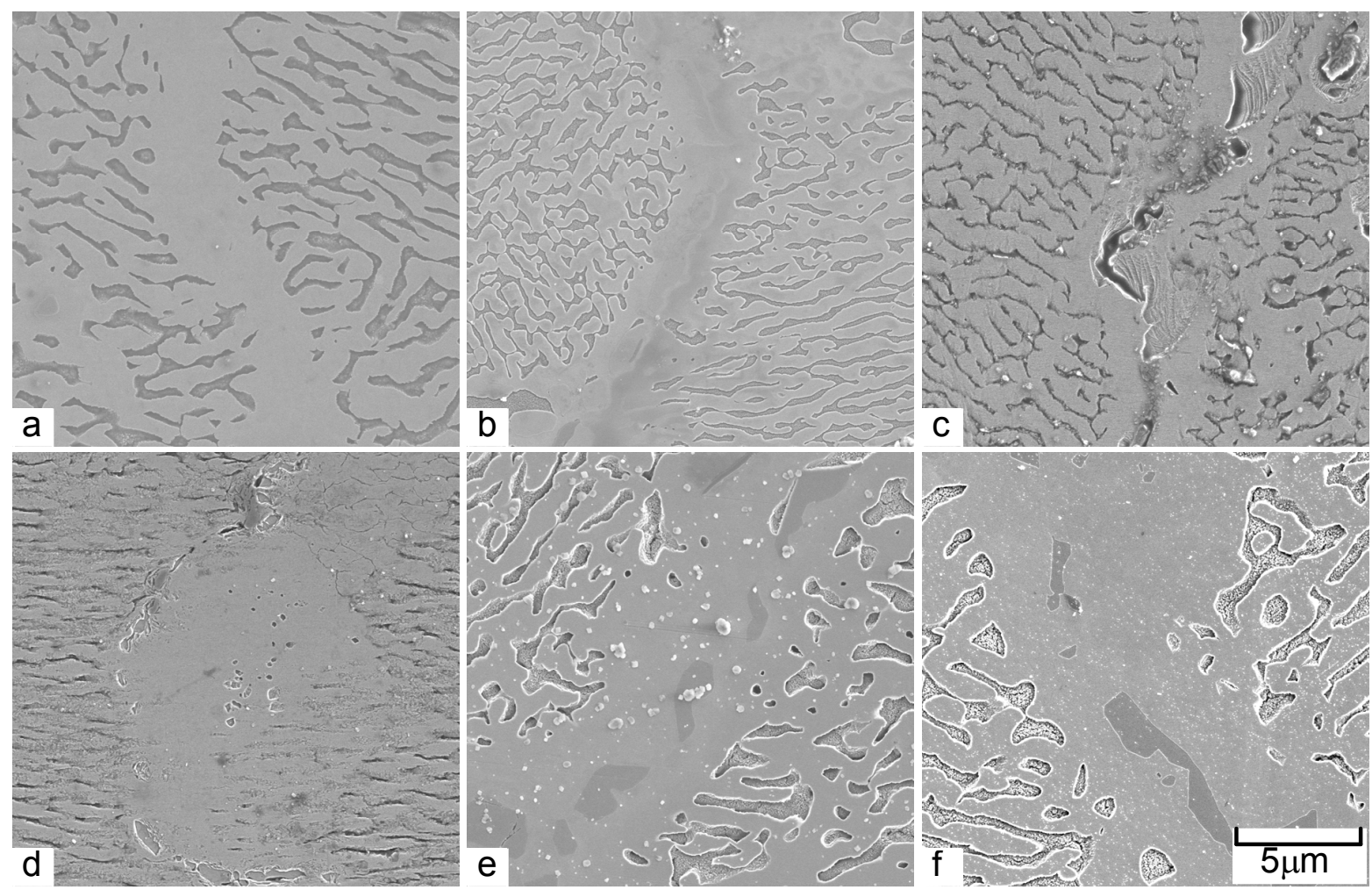

Fig.5 Scanning electron micrographs of the specimens creep ruptured at the stress of (a) 180, (b) 140, (c) 110, (d) 85, (e) 73.5 and (f) $70 \mathrm{MPa}$. 
initial stress of 180MP were covered by plate - like shaped $\gamma^{\prime}$ precipitates (Fig.4-(a)). The width of the plate - like shaped $\gamma^{\prime}$ precipitates is about $0.7 \mu \mathrm{m}$ at $180 \mathrm{MPa}$, and it increases with decreasing the stress and attains about 4.6 $\mu \mathrm{m}$ at 70MPa (Fig.4-(b)-(f)).

The scanning electron micrographs of the specimens creep ruptured at the stresses ranging from 70 to $180 \mathrm{MPa}$ are shown in Fig.5. The width of the plate - like shaped $\gamma$ ' precipitates is about $2.6 \mu \mathrm{m}$ at $180 \mathrm{MPa}$ and increases with decreasing the creep testing stress, and attaining about $7.8 \mu \mathrm{m}$ at $70 \mathrm{MPa}$ (Fig.5-(a) and (f)). Hence, the width of the plate - like shaped $\gamma$ ' precipitates of the creep ruptured specimens is wider than that of the creep interrupted specimens at the minimum creep rate, independent of stress.

To clarify the relation between the width of the plate - like shaped $\gamma^{\prime}$ precipitates and the creep testing time, attention is paid to the microstructure at the grain boundaries of the specimen at the same testing time. The scanning electron micrographs of the creep interrupted specimens at the minimum creep rate at 85 and $110 \mathrm{MPa}$, and the specimen creep ruptured at $140 \mathrm{MPa}$ are shown in Fig.6. The width of the plate - like shaped $\gamma^{\prime}$ precipitates is approximately $2.8 \mu \mathrm{m}$, independent of the stress. Consequently, the width of the plate - like shaped $\gamma^{\prime}$ precipitates strongly depends on the creep testing time, not on the stress at the constant temperature.

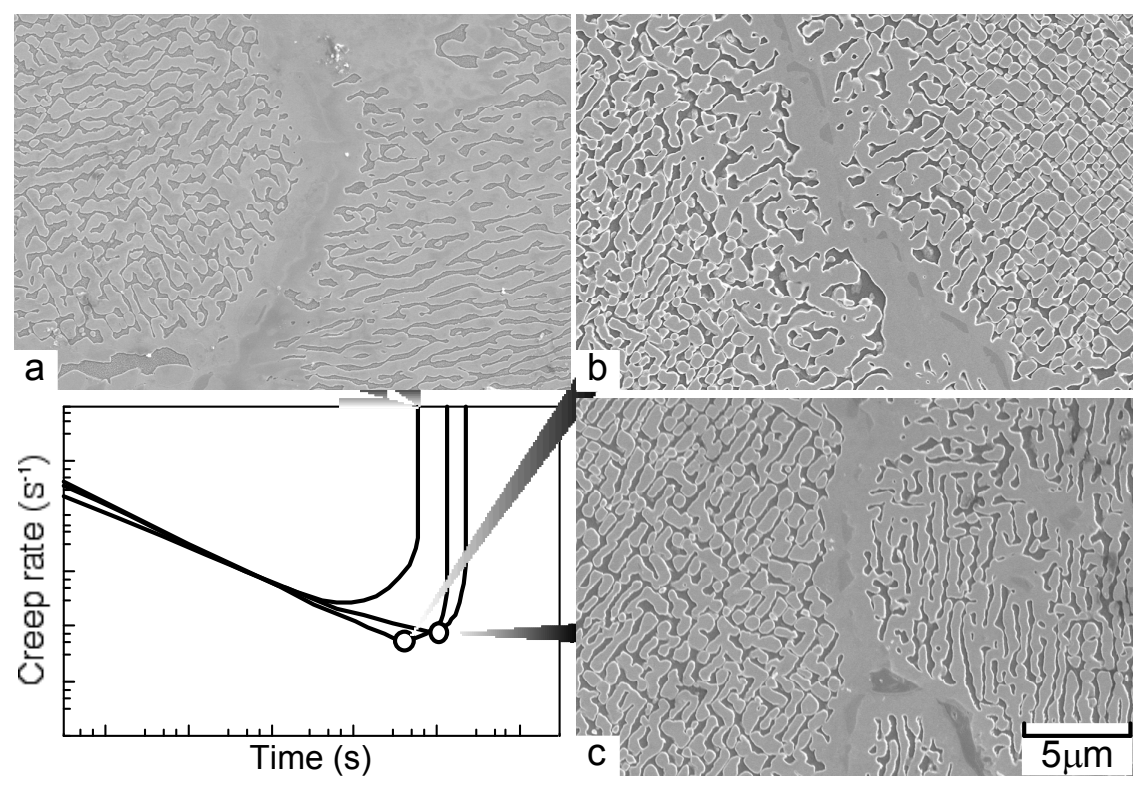

Fig.6 Scanning electron micrographs of (a) the specimen creep ruptured at $140 \mathrm{MPa}$ and the creep interrupted specimens at the minimum creep rate of (b) $110 \mathrm{MPa}$ and (c) $85 \mathrm{MPa}$.

\section{Dislocation substructure at vicinity of grain boundaries}

To investigate the effect of the plate - like shaped $\gamma^{\prime}$ precipitates at grain boundaries on creep deformation, the TEM observations are carried out at the vicinity of grain boundaries by using the creep interrupted and the ruptured specimens.

The transmission electron micrographs at the vicinity of grain boundaries of the creep interrupted specimens at 73.5, 140 and $180 \mathrm{MPa}$ are shown in Fig.7. There are few dislocations at the vicinity of grain boundaries and in the plate - like shaped $\gamma^{\prime}$ precipitates in all stress conditions. However, the dislocations are observed at the matrix phase near the interface between the matrix and the plate like shaped $\gamma^{\prime}$ precipitates. The number of dislocations at the interface increases with increasing the stress.

The transmission electron micrographs at the vicinity of grain boundaries of the specimens creep ruptured at 73.5, 140 and $180 \mathrm{MPa}$ are shown in Fig.8. No dislocations at the vicinity of grain boundaries and in the plate - like shaped $\gamma^{\prime}$ precipitates are observed On the contrary, a lot of dislocations exist near the interface between the matrix and the plate - like shaped $\gamma$ ' precipitates. In particular, a large number of dislocations which are tangled with each other are observed at the vicinity of the interface between the matrix and the plate - like shaped $\gamma^{\prime}$ precipitates at $180 \mathrm{MPa}$. And the strong contrast is seen at the vicinity of grain boundaries (Fig.8-(c)). These results suggested that the plate - like shaped $\gamma^{\prime}$ precipitates at the grain boundaries inhibit the dislocations movement for the grain boundaries. 


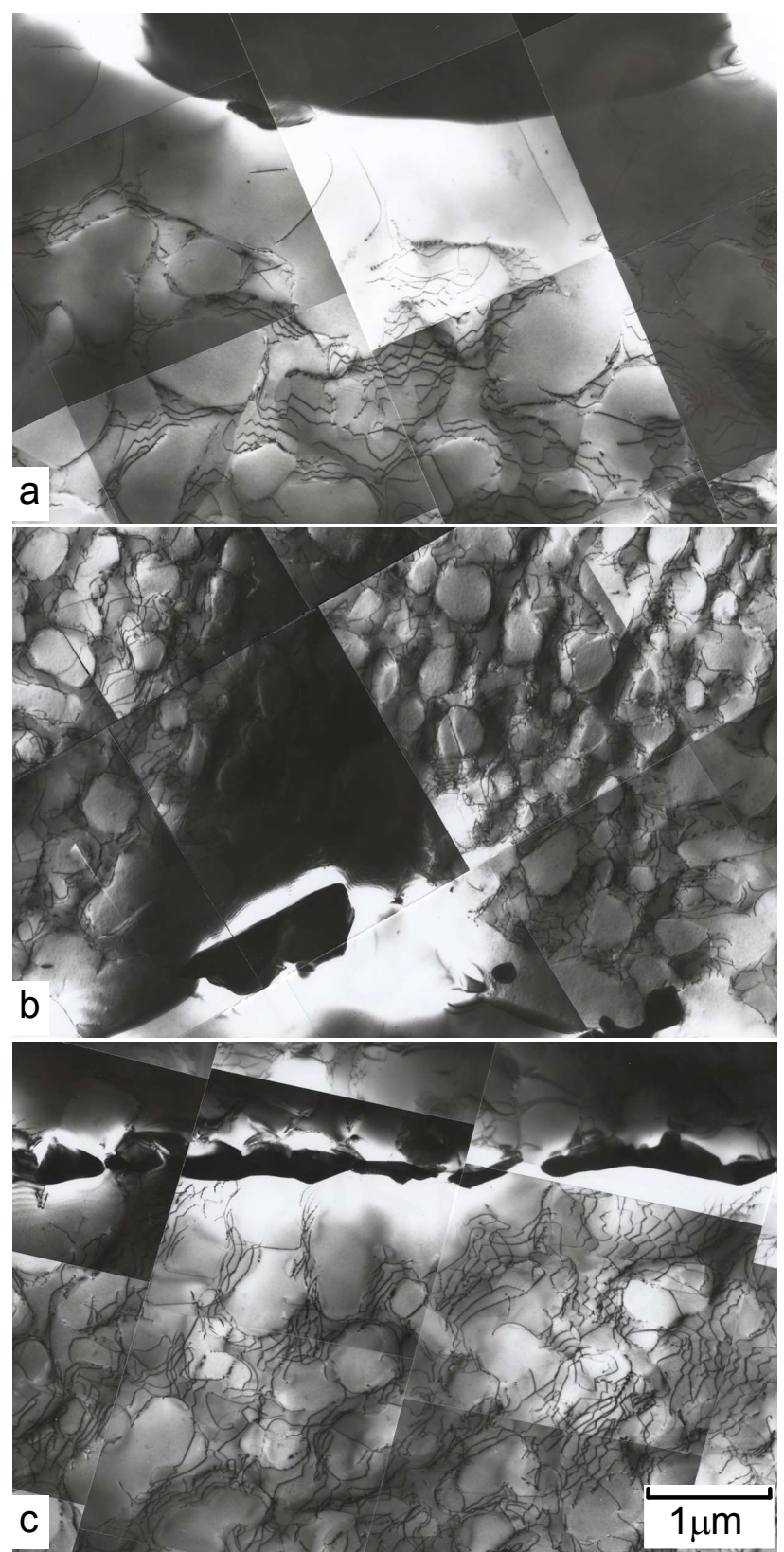

Fig.7 Transmission electron micrographs at the vicinity of grain boundaries of the specimens creep interrupted at (a) 73.5, (b) 140 and (c) $180 \mathrm{MPa}$.

The transmission electron micrograph at the grain interior of the specimen creep ruptured at $180 \mathrm{MPa}$ is shown in Fig.9. A large number of dislocations is observed at the rafted $\gamma / \gamma^{\prime}$ interfaces as well as in the matrix phase near the interface between the matrix and the plate - like shaped $\gamma^{\prime}$ precipitates (Fig.8-(c)). However, the week contrast is observed at the grain interior. On the other hand, the difference in the remarkable contrast was appeared at the vicinity of grain boundaries in the same specimen (Fig.8-(c)).
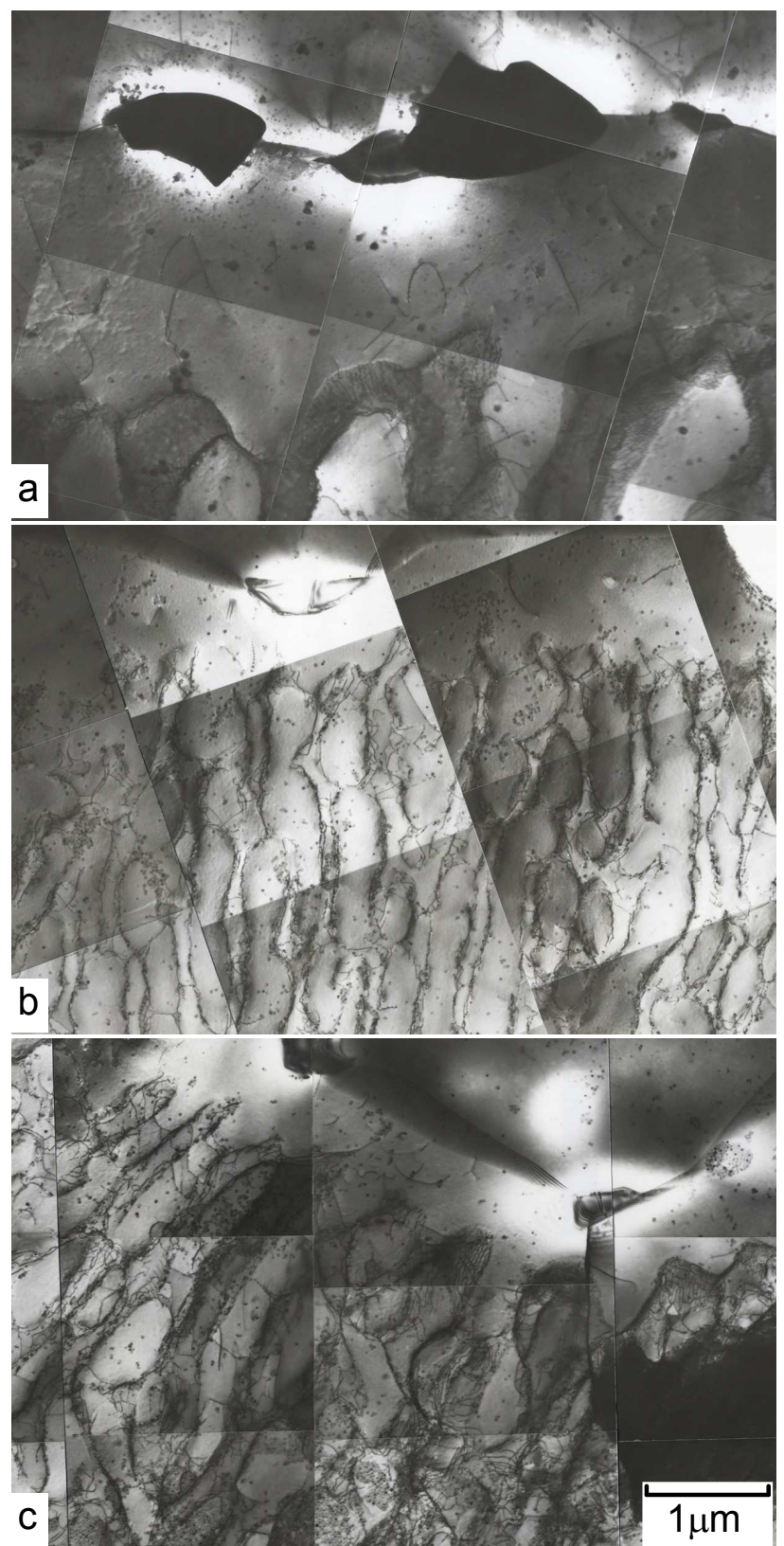

Fig. 8 Transmission electron micrographs at the vicinity of grain boundaries of the specimen creep ruptured at (a) 73.5, (b) 140 and (c) $180 \mathrm{MPa}$.

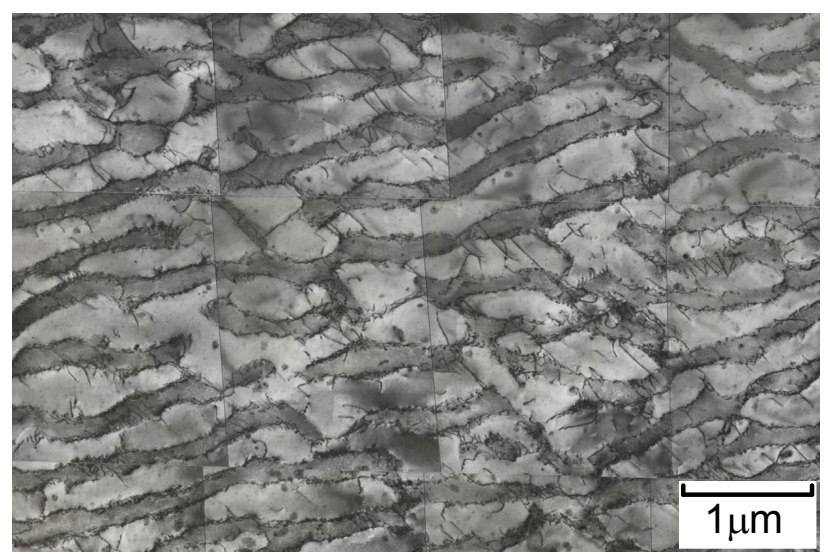

Fig.9 Transmission micrograph of the grain interior of the specimen creep ruptured at $180 \mathrm{MPa}$. 
Fig.10 shows the schematic illustration of the microstructure at the grain boundaries after creep ruptured. It is supposed that the strain concentrates around the grain boundary in comparison with the grain interior, that is, the drastic creep deformation occurred at the vicinity of grain boundaries.

Consequently, the plate - like shaped $\gamma^{\prime}$ precipitates at the

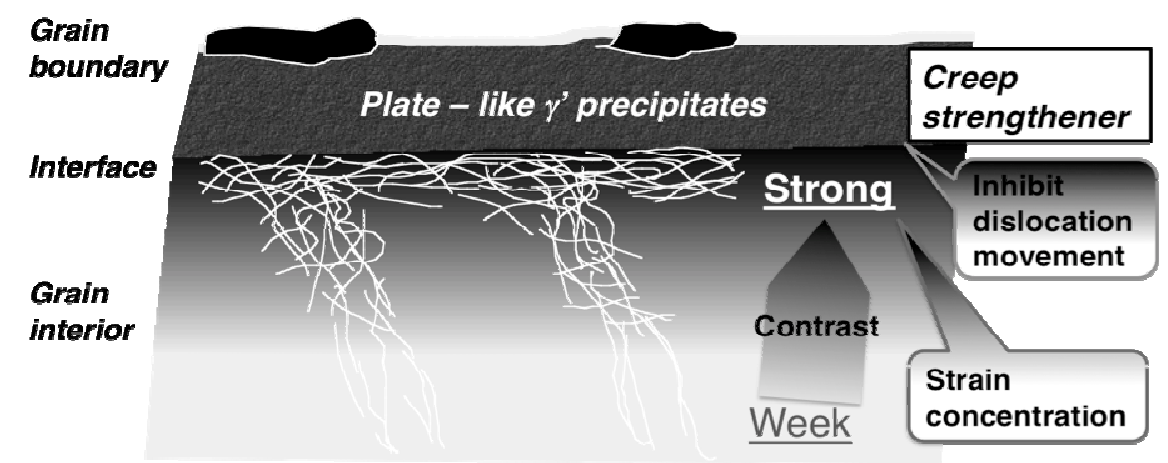

Fig.10 Schematic illustration of the microstructure at the grain boundaries after creep ruptured. grain boundaries seems to inhibit the dislocations movement and act as the creep strengthener.

\section{Summary}

The change in the morphology of $\gamma^{\prime}$ precipitates and the dislocation substructures at the vicinity of grain boundaries with creep deformation are investigated on a polycrystalline nickel-based superalloy, IN-100. The following conclusions are obtained.

1) Subjecting the creep deformation, the plate - like shaped $\gamma^{\prime}$ precipitates are precipitated at the grain boundaries.

2) The width of the plate - like shaped $\gamma^{\prime}$ precipitates increases with decreasing the stress. However, it strongly depends on the creep testing time.

3) There are few dislocations at the vicinity of grain boundaries and in the plate - like shaped $\gamma^{\text {' }}$ precipitates in all stress conditions. On the contrary, a lot of dislocations are observed near the interface between the matrix and the plate - like shaped $\gamma^{\prime}$ precipitates.

4) The TEM observations on the creep ruptured specimens indicated that the strong contrast is observed at the vicinity of grain boundaries, but week contrast in the grain interior.

5) Consequently, the plate - like shaped $\gamma$ ' precipitates at the grain boundaries seems to inhibit the dislocations movement and act as the creep strengthener.

\section{References}

[1] T. M. Pollock and A. S. Argon : Acta Metall. Mater., Vol.42 (1994), p.1859.

[2] V. Sass, V. Glatzel and M. F. Kniepmeier : Acta Metall. Mater. Vol.44 (1996), p.1967.

[3] Y. Kondo, N. Kitazaki, J, Namekata, N. Ohi and H. Hattori : Proc. of the 8th Int. Conf. on Superalloys 1996, (1996), p.297.

[4] U. Tetzlatt and H. Mughrabi : Proc. of the 9th Int. Conf. on Superalloys 2000, (2000), p.273.

[5] N. Miura, Y. Kondo and T. Matsuo : Proc. of 9th Int'1. Conf. on Creep and Fracture Eng. Mater. and Structures, (2001), p. 437.

[6] L. Shui, S. Tian, T. Jin. and Z. Hu : Mater. Sci. and Eng. A, Vol.418 (2006), p.229.

[7] N. Ohi and H. Hattori : JSPS Rep. of the 123rd Committee on Heat Res. and Alloys, Vol.33 (1992), p.195.

[8] H. Nagai, K. Yokokawa, H. Yoshisu, K. Kimura and K. Yagi : Tetsu-to-Hagane, Vol.81 (1995), p.667.

[9] N. Miura, Y. Kondo and T. Matsuo : Tetsu-to-Hagane, Vol.90 (2004), p.567. 